\title{
CÃES DOMÉSTICOS EM UNIDADES DE CONSERVAÇÃO: IMPACTOS E CONTROLE
}

\section{DOMESTIC DOGS IN PROTECTED AREAS: IMPACTS AND CONTROL}

\author{
Ana Luiza Oliveira Vilela ${ }^{1}$; Valdir Lamim-Guedes ${ }^{2}$ \\ ${ }^{1}$ Pós-graduada em Gestão e Análise Ambiental pela Faculdade Victor Hugo. E-mail: \\ anavilela_bio@hotmail.com \\ ${ }^{2}$ Professor no Centro Universitário Senac, São Paulo, SP. E-mail: \\ dirguedes@yahoo.com.br
}

\begin{abstract}
RESUMO
Cães domésticos (Canis lupus familiaris L., Canidae) têm atuado como espécie exótica perturbando e modificando ecossistemas nativos de diferentes maneiras. Esses animais, estando em ambiente natural, retornam ao estado selvagem passando a ser chamados ferais. A presença destes cães é uma situação grave levando-se em conta a possibilidade de declínio das populações de diversos animais nativos, incluindo a redução das populações de presas para os carnívoros silvestres, e por serem uma via de entrada de muitas doenças contagiosas para os animais nativos. Neste texto será tratado dos impactos de cães ferais em Unidades de Conservação, conflitos socioambientais e formas de controle das populações destes animais.
\end{abstract}

Palavras-chave: Conflitos Socioambientais. Invasão Biológica. Declínio de Espécies. Manejo de Unidades de Conservação. Competição.

\begin{abstract}
ABSCTRACT
Domestic dogs (Canis lupus familiaris L., Canidae) have acted as exotic species, disrupting and modifying native ecosystems with different ways. When in natural environments, those animals return to an wild state, becoming called feral. The presence of these dogs causes a serious situation, because they bring the possibility of declining many native animals' populations, the reduction of prey populations for wild carnivores as well as a gateway to many contagious diseases to native animals. On this text will be treated the impacts of feral dogs in protected areas, the environmental conflicts, and ways of control those animals' populations.
\end{abstract}

Keywords: Environmental Conflicts. Biological Invasion. Decline of Species. Management of Protected Areas. Competition.

\section{INTRODUÇÃO}

Entre as várias ameaças que recaem sobre os remanescentes florestais, o contato dos animais domésticos com os animais nativos cresceu com um consequente aumento no potencial de transmissão de doenças, predação e competição. Ameaças "invisíveis", como a caça clandestina e a predação por cães e gatos domésticos, seu impacto potencial como a transmissão de vírus e outros 
tipos de infecção na vida silvestre revelam uma visão altamente preocupante que afeta ecossistemas cada vez mais ameaçados e que podem perder por completo suas floras e faunas endêmicas (CERQUEIRA e FREITAS, 1999).

A distribuição das espécies em todos os continentes tem sido limitada pela crescente exploração das áreas naturais - como o desmatamento e caça -, e com a expansão da agropecuária e das cidades. Atualmente, grande parte da vegetação nativa - como na mata atlântica e cerrado -, apresenta uma distribuição fragmentada, povoada por pequenas populações. Desta forma, a dispersão das espécies nativas é impedida por barreiras impostas pelo homem, prejudicando o deslocamento para novas áreas e, em muitos casos, a diversidade genética destas populações.

Verifica-se que a ausência de interação genética com outras populações da mesma espécie, ocasiona deriva gênica e endocruzamentos (MMA, 2000b). Desde 1600, cerca de 18\% das extinções com causas conhecidas foram devido à introdução de espécies exóticas (PITÉ e AVELAR, 1996), cujos problemas à nossa fauna ocorrem há décadas sem, no entanto, temos tido oportunidade real de nos posicionarmos com relação a estratégias eficazes de resolução de várias situações com que nos defrontamos atualmente.

\section{CÃES FERAIS}

A introdução de organismos exóticos e animais ferais, incluindo cães, gatos, cavalos, porcos e outros vertebrados vem causando um impacto drástico nas espécies nativas, especialmente, em ilhas ou em populações isoladas. Um animal é classificado como feral quando se trata de um animal doméstico que vive em um hábitat selvagem, sem alimentos ou abrigo fornecidos por humanos, e que mostra certa resistência ao contato com pessoas (BOITANI, 1995).

Os efeitos da presença de cães ferais em Unidades de Conservação (UCs) no Brasil sobre a vida selvagem nativa ainda são pouco conhecidos. Sabe-se que a caça clandestina e a fragmentação florestal têm um efeito decisivo na redução das populações de aves e mamíferos de grande porte, mas o impacto dos gatos e cães ferais ainda é menosprezado (CHIARELLO, 2000).

O cão doméstico (Canis lupus familiaris L., Canidae) adaptou-se a diferentes habitats, exceto florestas úmidas e desertos. É a espécie que possui a distribuição natural mais ampla entre os mamíferos terrestres, depois do homem. A origem do cão doméstico ainda é incerta, evidências obtidas a partir de genoma mitocondrial indicam que a origem pode ter acontecido na Europa, entre 18.800-32.100 anos atrás (THALMANN et al., 2013) ou no sudeste asiático, a menos de 16.300 anos (PANG et al., 2009). Posteriormente, o cão foi levado pelo homem para o restante do mundo, passando a ser uma espécie exótica invasora (EEI), ou seja, uma espécie que se estabelece em um novo ecossistema ou habitat fora de sua distribuição natural, tornando-se agente de mudança que ameaça, em algum grau, a biodiversidade nativa, os recursos naturais e/ou a saúde humana (ZILLER, 2004).

A Convenção sobre a Diversidade Biológica (CDB), da qual o Brasil é signatário, estabelece que se deva prevenir e impedir a entrada de espécies exóticas em novos ambientes, assim como controlar ou erradicar espécies exóticas invasoras que ameacem os ecossistemas, habitats ou espécies (MMA, 2000a). A preocupação com a invasão de cães nas UCs vem aumentando nas últimas décadas. Especificamente com relação à fauna exótica, algumas medidas para eliminá-las de algumas UCs foram providenciadas, sem, no entanto, resultar na solução dos problemas existentes. 


\section{A ENTRADA DE CÃES EM UNIDADES DE CONSERVAÇÃO}

Grande parte da entrada de cães em unidades de conservação se dá pelo descaso da população do entorno das UCs, devido à soltura indevida, muitas vezes de forma proposital, mesmo que a intenção não seja causar danos ao ambiente em si, mas para livrar-se de animais que se tornaram indesejados, seja por falta de recursos, técnicas adequadas de criação ou impossibilidade de lucro imediato (CAMPOS, 2004). Os cães são eficientes predadores de ninhos, roedores, marsupiais, além de transmitir diversas doenças para as espécies nativas (BUTTLER et al., 2004; CAMPOS, 2004).

Srbek-Araujo e Chiarello (2008) observaram vários cães da comunidade do entorno que frequentavam periodicamente a mata nativa na Estação Biológica de Santa Lúcia, Santa Teresa, Espírito Santo. Esse reconhecimento foi possível através de armadilhas fotográficas colocadas dentro da Estação Biológica e posterior visitação as casas do entrono. Os cães ficavam soltos, fugiam ou eram abandonados pelos seus donos, procurando abrigo e alimento dentro da mata nativa.

Vilela (2009) registrou atividade de caça com o uso de cachorros no Parque Estadual Nova Baden (PENB) em Lambari, Minas Gerais. Alguns dos cachorros se perdiam de seus donos e vagavam pelo parque. Segundo funcionários do PENB, algumas vezes veados [Mazama americana Erxleben (1777), Cervidae] foram perseguidos pelos cães dentro do parque, em uma destas situações, os caçadores ao perceberem a presença de outras pessoas na área, fugiram deixando os cães abaterem um veado (Figuras 1 a 3). Esses cães foram apreendidos pela equipe do PENB.

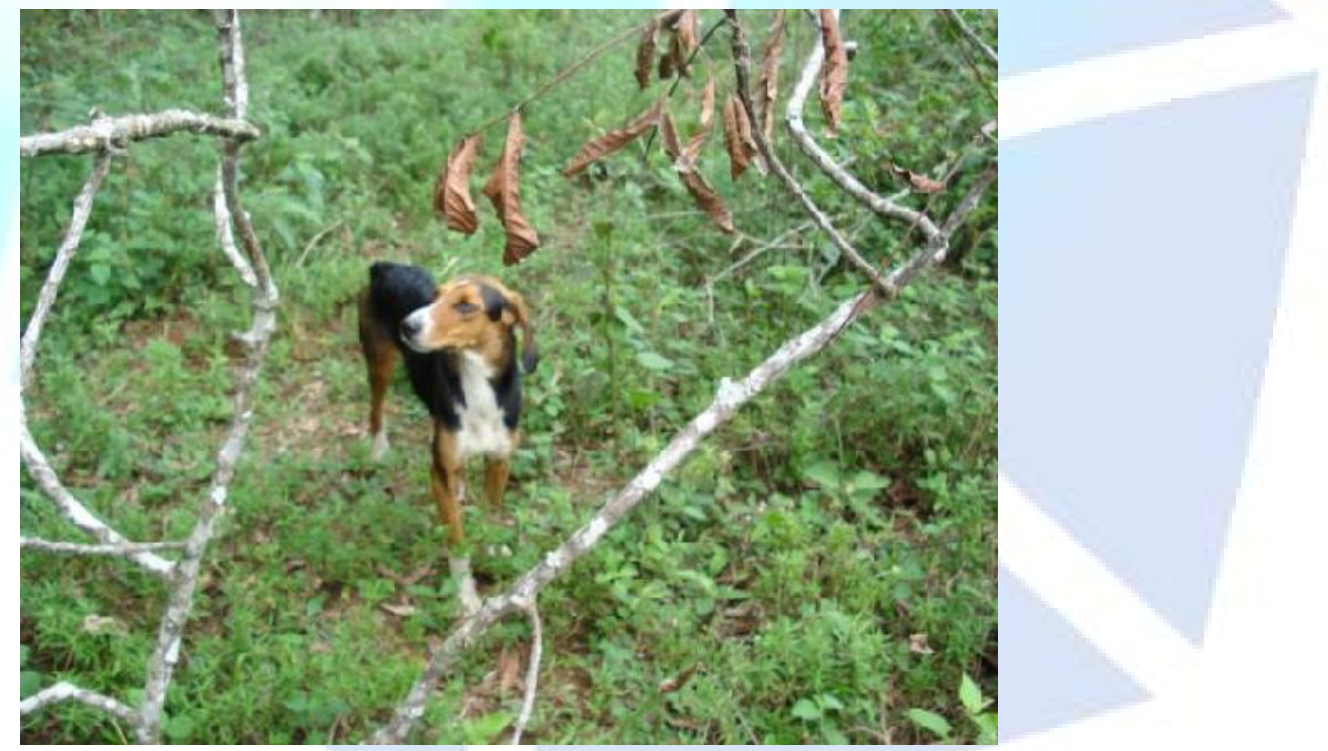

Figura 1. Cachorro de caça encontrado dentro do Parque Estadual Nova Baden (PENB) em Lambari, Minas Gerais. Fonte: A.L.V. Oliveira (autor). 


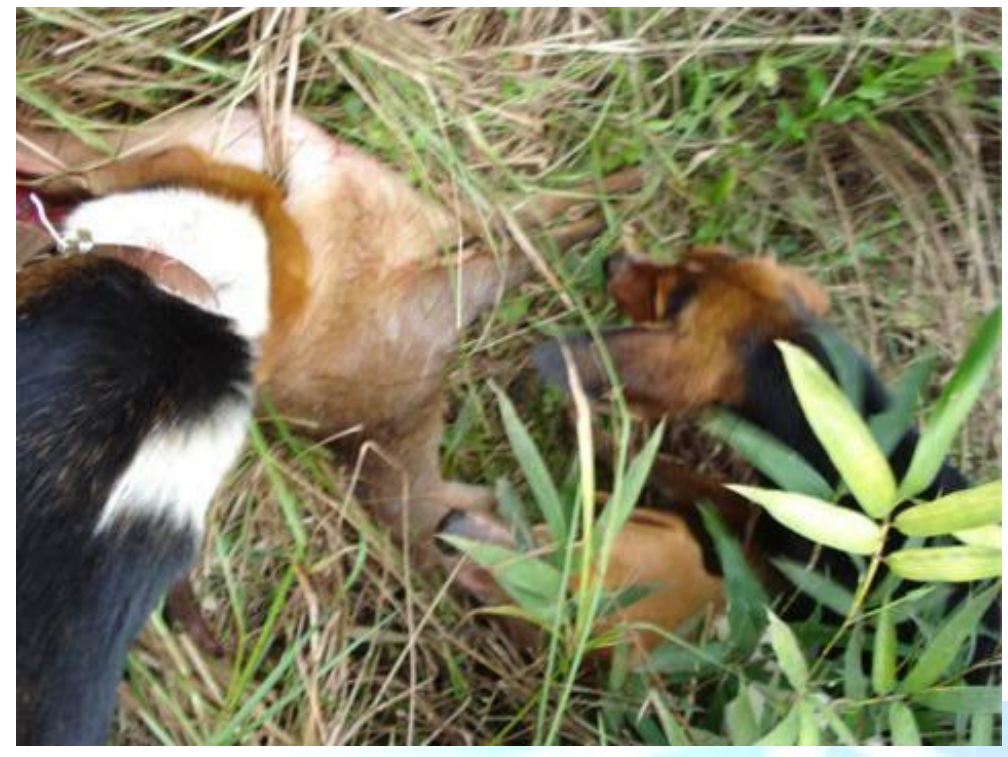

Figura 2. Cachorros abateram veado (Mazama americana), dentro do Parque Estadual Nova Baden (PENB) em Lambari, Minas Gerais. Fonte: A.L.V. Oliveira (autor).

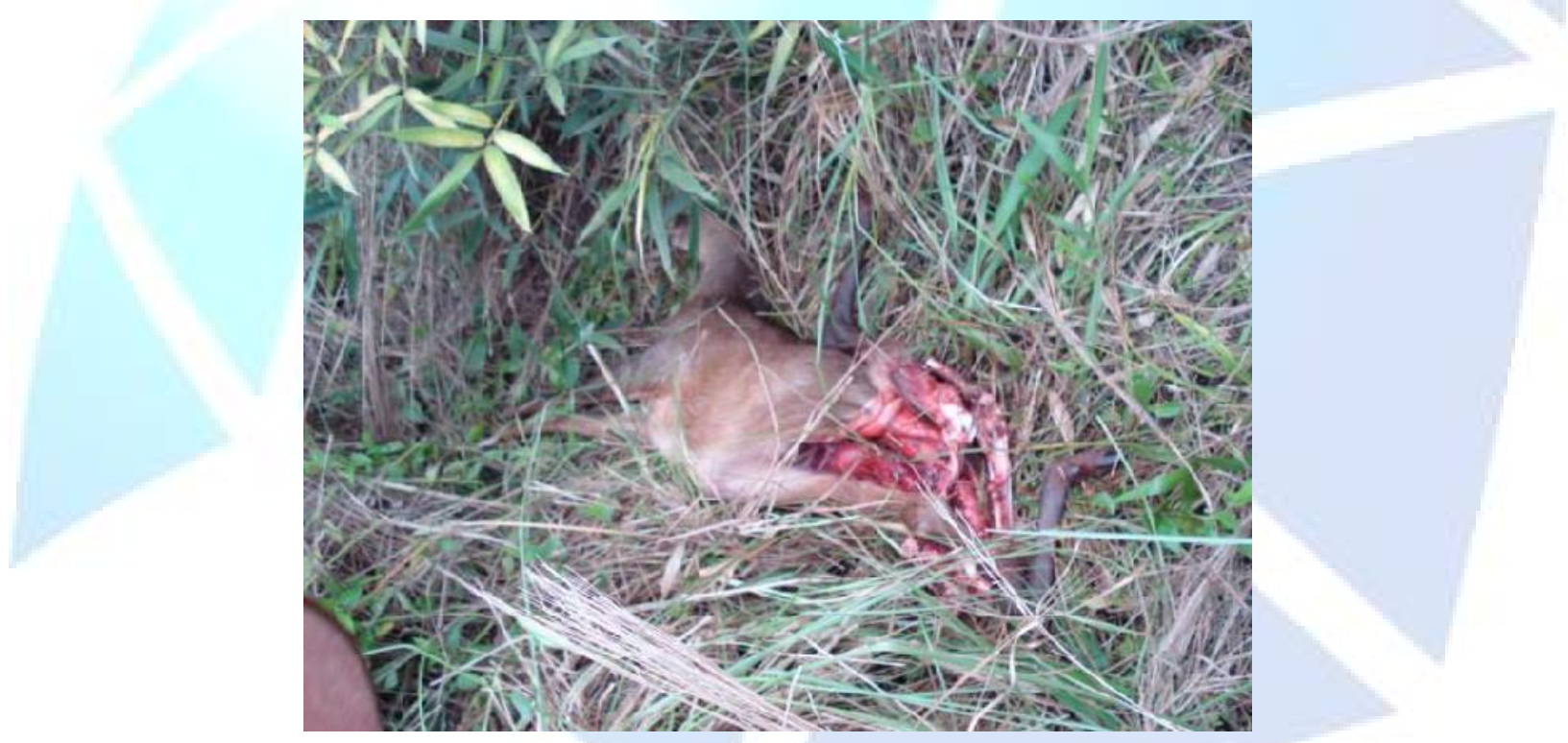

Figura 3. Veado (Mazama americana) abatido por cães no Parque Estadual Nova Baden (PENB) em Lambari, Minas Gerais. Fonte: A.L.V. Oliveira (autor).

Os registros mais significativos nas UCs paranaenses têm sido da presença de cães domésticos circulando, vocalizando, em matilhas ou isolados, explorando a borda nas áreas das Unidades de Conservação de proteção integral (ZILLER e ZALBA, 2007). Na Estação Ecológica São Camilo, Palotina (PR), cães domésticos têm gerado a necessidade de controle por parte da gerência da UC. Este controle tem sido executado com base em tentativas de erradicação dos animais quando avistados no interior da UC, face aos inúmeros problemas que causam à fauna silvestre nativa local (CARVALHO, 2004). Segundo Mikich e Oliveira (2003), um problema conhecido há muitos anos é a presença de cães domésticos no Parque Estadual Vila Rica do Espírito 
Santo, Fênix (PR). A forma de resolução inicialmente utilizada foi a erradicação quando do avistamento, por meio de caça autorizada.

Matilhas de cães ferais foram também encontradas no Parque Estadual da Ilha do Mel (PR), sobrevivendo da predação de siris, caranguejos, pássaros e lagartos. Uma tentativa de esterilizar cães em comunidades próximas ao parque não teve êxito, pois os moradores não foram devidamente esclarecidos dos motivos de tal procedimento, com apenas 140 cães castrados e vacinados (ZILLER e ZALBA, 2007).

\section{COMPETIÇÃO COM ESPÉCIES NATIVAS}

A competição interespecífica é uma interação ecológica antagonística onde duas espécies diferentes disputam um mesmo nicho ecológico, uma delas inevitavelmente será favorecida e assumirá vantagens em relação à outra. Segundo Primack e Rodrigues (2001), muitas das espécies exóticas não se estabelecem nos lugares nos quais foram introduzidas, pois o ambiente geralmente não é adequado às suas necessidades. Contudo, algumas espécies conseguem se instalar em seu novo habitat e muitas delas crescem em abundância à custa das espécies nativas. A principal razão pela facilidade que as espécies exóticas possuem para invadir e dominar novos ambientes e deslocar espécies nativas é a ausência de seus predadores naturais, doenças e parasitas no novo ambiente.

Além de seu papel como predadores, os cães podem ter um impacto na comunidade também por meio da competição. Buttler et al. (2004) afirmam que os cães domésticos não são significativamente competitivos em relação aos grandes predadores africanos, devido à sua baixa capacidade de atacar e matar grandes presas. Na região neotropical, cães podem competir com grandes felinos, como onça-pintada (Panthera onca L., 1758, Felidae) e a onça-parda (Puma concolor L., Felidae), e com carnívoros menores como jaguatiricas (Leopardus pardalis L., 1758, Felidae), raposas (Cerdocyon thous L., 1766, Canidae), entre outros, mas ainda faltam dados de campo para comprovar isso. Cães podem ser predados por espécies nativas, por exemplo, foram encontrados restos de cães domésticos nas fezes de onça-parda na Venezuela (FARREL et al., 2000). Esta evidência pode ser considerada positiva, pois representa uma forma de controle natural da população de cães dentro de UCs, no entanto, deve-se levar em consideração os riscos de contaminhação biológica (discutidos a seguir).

No Parque Estadual Vila Rica do Espírito Santo, Paraná, foram encontrados, no interior da mata, dois catetos mortos (Pecari tajacu L., 1758, Tayassuidae) e próximo a borda da vegetação uma paca (Cuniculus paca L. 1766, Cuniculidae) e mais um cateto mortos por cachorros domésticos. Esta UC possui uma área de 353,86 ha, pequena, portanto, para os padrões de sobrevivência de populações de mamíferos de médio-grande porte, que vivem em fragmentos florestais isolados, ou com pouco contato com outras populações da mesma espécie (ZILLER, 2004).

Os dados sobre a predação de vertebrados por cães ferais foram coletados na Reserva de Santa Genebra em Campinas, São Paulo, de abril de 1988 a dezembro de 1991 (GALETTI e SAZIMA, 2006). Os cães ferais normalmente procuravam por alimentos à noite e foram avistados durante o dia em três ocasiões com grupos de 3-6 indivíduos. No total, 46 carcaças de 12 espécies identificadas foram encontradas mortas por cães na Reserva de Santa Genebra durante os 44 meses do estudo, sendo que normalmente os ataques terminavam na mutilação indiscriminada da presa.

Os cães ferais perseguiam e matavam vários tipos de vertebrados, que variavam de relativamente pequenos, como a rã-pimenta [Leptodactylus labyrinthicus (Spix, 1824), Leptodactylidae], com cerca de $250 \mathrm{~g}$, até presas de grande porte, como o veado-catingueiro (Mazama gouazoubira G. Fischer, 1814, Cervidae), com aproximadamente $10 \mathrm{~kg}$. O alto impacto dos cães ferais em alguns tipos de mamíferos é provavelmente a causa principal da extinção de 
diversas espécies na Reserva de Santa Genebra, como a paca, o veado-catingueiro e a cutia (Dasyprocta azarae Lichtenstein, 1823, Dasyproctidae) (GALETTI e SAZIMA, 2006).

Os efeitos da extinção desses frugívoros-herbívoros na área poderiam comprometer seriamente a herbivoria e a dispersão de sementes da flora local (DIRZO e MIRANDA, 1991). Por exemplo, a cutia é o único dispersor de sementes do jatobá (Hymenaea courbaril L., Fabaceae), e não há dispersão das sementes dessa espécie em Santa Genebra (HALLWACHS, 1986).

A predação de um macho adulto de macaco-prego [Cebus nigritus (Goldfuss, 1809), Cebidae], por dois cães domésticos é relatada no interior do Parque Estadual da Serra do Brigadeiro, localizado na Mata Atlântica do sudeste de Minas Gerais (OLIVEIRA et al., 2008). A observação foi registrada em local de mata nativa bem preservada, a cerca de $800 \mathrm{~m}$ da borda mais próxima da reserva. Embora este seja o primeiro registro confirmado de predação por cão doméstico nesta UC, dados de estudo sobre a mastofauna local, usando o registro de pegadas, indica que o cão doméstico é a espécie de mamífero mais frequente, sugerindo que sua presença é constante e amplamente distribuída na área (OLIVEIRA et al., 2008).

Lacerda et al. (2009) relataram que a presença de cães domésticos no Parque Nacional de Brasília tem diminuído a área efetivamente protegida para duas espécies ameaçadas de extinção: o lobo-guará [Chrysocyon brachyurus (Illiger, 1815), Canidae] e o tamanduá-bandeira (Myrmecophaga tridactyla L., 1758, Myrmecophagidae). A ocorrência dessas espécies foi maior em áreas internas (distantes mais de $3 \mathrm{~km}$ da borda), onde os cães não estavam presentes, ou seja, o efeito de borda é intensificado pela presença dos cães domésticos na área.

O impacto de cães domésticos pode afetar até mesmo a cadeia alimentar de predadores de topo, como a onça-pintada e a onça-parda. Por serem predadores oportunistas, a onça-pintada e a onça-parda consomem presas em relação à abundância das mesmas, atingindo organismos de vários níveis tróficos e realizando o controle populacional. Essas presas geralmente são herbívoros que podem participar da dispersão de sementes ou da polinização. Com a alta predação por cães domésticos, em estado feral ou não, porém, há uma diminuição nas presas das onças e outros carnívoros, o que pode levar estas a predar animais domésticos ou levando as populações destas espécies ao declínio. Na ausência desses predadores de topo, a tendência é que populações de espécies herbívoras aumentem e, ao se utilizarem de um maior número de frutos e sementes, podem alterar a regeneração de uma floresta (TERBORGH, 1990).

\section{DISSEMINAÇÃO DE DOENÇAS}

Espécies exóticas também são responsáveis pela introdução de inúmeros micro-organismos, que podem causar doenças e parasitoses às espécies nativas. Quando uma área recebe animais que não fazem parte da sua fauna natural devem ser considerados alguns riscos: 1) possibilidade da introdução de novas doenças transmissíveis, 2) possibilidade da introdução de novos reservatórios para os agentes etiológicos de doenças pré-existentes e 3) a possibilidade da criação de um desequilíbrio ambiental com interferência sobre a fauna local (LENNETTE e EMMONS, 1972).

Aspectos clínicos e patológicos da onça-pintada foram em sua maioria descritas em animais em cativeiro e refletem que doenças infecciosas são comuns entre indivíduos que tem contato com animais domésticos, como cães e gatos. Sob esse ponto de vista, a presença de cachorros e gatos domésticos na unidade de conservação e seu entorno propicia o contato destas com espécies silvestres com grandes chances de disseminação de doenças. Algumas doenças infecciosas causadas por fungos e bactérias como a antracose, tuberculose, esporotricose, histoplasmose e paracoccidiodomicose foram estudadas em onça-pintada por Abdulla et al. (1982) e Costa et al. (1997). 
Faraco e Lacerda (2004), analisando os problemas causados por animais domésticos no Brasil, encontraram registros clínicos de lobos-guarás em cativeiro que vieram a óbito devido à parvovirose canina, o que demonstra a suscetibilidade desta espécie ao vírus, bem como a cinomose canina, encontrada em 1987 na última população de furões [Mustela nigrepes (Audubon e Bachman, 1851), Mustelidae] no meio selvagem nos Estados Unidos (PRIMACK e RODRIGUES, 2001). Outra constatação ocorreu no Parque Nacional do Serengueti, Tanzânia, onde pelo menos $25 \%$ dos leões (Panthera leo L., Felidae) foram mortos por cinomose e parvovirose, doenças contraídas a partir dos cerca de 30.000 cães domésticos viventes ao redor da reserva (FARACO e LACERDA, 2004).

Segundo Ziller (2004), a Secretaria de Vigilância Ambiental de Santa Teresa, de março de 2002 a dezembro de 2003, 328 cães foram retirados das vias públicas ou estradas do município, a maioria dos quais $(68,0 \%)$ foi sacrificada (os restantes devolvidos aos seus proprietários ou foram adotados por outros). Duas importantes ações são executadas por este setor: controle de doenças (raiva e a leishmaniose, por meio de vacinação de indivíduos saudáveis e do sacrifício de cães doentes) e controle da população de cães de rua (captura e eliminação). Em relação à Leishmaniose, 15 cães foram suspeitos de estarem infectados em 2002 e quatro em 2003 (quatro animais foram sacrificados no primeiro e uma no segundo ano, após a confirmação positiva através de análise laboratorial). Neste sentido, este programa provavelmente contribuiu para a preservação de espécies de mamíferos nativos, eliminando ou reduzindo consideravelmente a população de cães, que são potenciais vetores de doenças. As ações de controle de zoonoses devem assim ser incluídas na lista de prioridades para a conservação de espécies nativas, especialmente, em zonas de contato como o ambiente rural e áreas próximas a unidades de conservação (BUTTLER et al., 2004).

\section{ATAQUES DE CÃES FERAIS A ANIMAIS DOMÉSTICOS}

Os cães ferais atacam animais domésticos como bovinos, caprinos, porcos e aves, no entanto, estes ataques muitas vezes são atribuídos a animais nativos como onças-pintadas, onçaspardas, lobos-guarás e outros, sendo estes perseguidos e mortos devido às perdas de animais nas propriedades. A identificação da maioria das predações por meio das carcaças permite a atribuição de alguns desaparecimentos aos ataques de onças ou cães ferais (Tabela 1). Apesar da dificuldade de confirmar a causa real dos desaparecimentos, a população atribuiu tais perdas ao ataque de onças, gerando conflitos. Segundo Palmeira e Barrella (2007), em comunidades quilombolas localizadas em Iporanga, Vale do Ribeira, Sudeste de São Paulo, os entrevistados não sabiam as diferenças entre a predação causada pelas duas espécies de onças, nem por cães, entretanto, atribuíram a maioria dos ataques $(84 \%)$ à onça-pintada.

É muito importante diferenciar ataques de grandes felinos daqueles realizados por cães, que podem se reunir em bandos e causar graves danos em regiões de atividade pecuária. Na Tabela 1, há um resumo de características que ajudam a diferenciar a espécie do animal responsável pelo ataque. Maiores detalhes estão disponíveis em Hoogesteijn (2004) e Oliveira et al. (2008).

Os cães podem matar suas presas individualmente ou em bandos. As presas apresentam feridas nos membros posteriores com evidência de mordidas e ataques antes da morte (veja a Figura 3). Às vezes as presas não são consumidas e se vê ao seu redor as pegadas características (HOOGESTEIJN, 2004). A maioria dos ataques seria relacionada a jogos instintivos de predadorpresa, em vez de a caça para obtenção de alimentos (LACERDA et al., 2009). 
Tabela 1 - Diferenciação entre ataques de onças pintadas, onças pardas e cães ferais. Copilado a partir de Hoogesteijn (2004) e Oliveira e Cavalcanti (2002).

\begin{tabular}{|c|c|c|c|}
\hline Características & Onça-pintada & Onça-parda & Cão doméstico \\
\hline Tipo de presa & $\begin{array}{c}\text { Ataca animais de grande } \\
\text { porte como bovinos e } \\
\text { equinos. }\end{array}$ & $\begin{array}{c}\text { Ataca animais médio } \\
\text { porte: ovinos, bezerros e } \\
\text { potros novos. }\end{array}$ & $\begin{array}{c}\text { Ataca animais de pequeno } \\
\text { e médio porte. }\end{array}$ \\
\hline $\begin{array}{c}\text { Método de } \\
\text { ataque/abate }\end{array}$ & $\begin{array}{l}\text { Mata por fratura da base } \\
\text { do crânio ou atlas e âxis. }\end{array}$ & $\begin{array}{c}\text { Mata por sufocamento ou } \\
\text { hemorragia devido a } \\
\text { incisão na jugular da } \\
\text { presa. }\end{array}$ & $\begin{array}{l}\text { Arranca pele da cabeça e } \\
\text { do dorso, morde orelhas e } \\
\text { focinho e na maioria das } \\
\text { vezes não mata o animal. }\end{array}$ \\
\hline Partes consumidas & $\begin{array}{l}\text { As primeiras partes } \\
\text { devoradas são as } \\
\text { anteriores como rosto, } \\
\text { pescoço e região peitoral } \\
\text { sendo que comumente as } \\
\text { partes posteriores são } \\
\text { deixadas intactas. }\end{array}$ & $\begin{array}{l}\text { Consomem geralmente as } \\
\text { costelas e a área detrás } \\
\text { destas, fígado, coração e } \\
\text { pulmões e a musculatura } \\
\text { das patas posteriores, } \\
\text { quase sempre pela porção } \\
\text { ventral. }\end{array}$ & $\begin{array}{l}\text { Geralmente não chega a } \\
\text { se alimentar do animal. }\end{array}$ \\
\hline $\begin{array}{c}\text { Local de } \\
\text { alimentação }\end{array}$ & $\begin{array}{l}\text { Pode arrastar presa por } \\
\text { até } 1,5 \mathrm{~km} \text { para locais } \\
\text { com vegetação densa, } \\
\text { para proteção contra } \\
\text { outros predadores e aves } \\
\text { necrófagas. }\end{array}$ & $\begin{array}{l}\text { Arrasta a presa por até } \\
\text { algumas centenas de } \\
\text { metros, geralmente cobre } \\
\text { a presa com folhas secas } \\
\text { para posterior } \\
\text { alimentação. }\end{array}$ & $\begin{array}{c}\text { Alimenta-se no local ou } \\
\text { arrasta a presa a curta } \\
\text { distância. }\end{array}$ \\
\hline
\end{tabular}

\section{CONTROLE DE CÃES FERAIS EM ÁREAS NATURAIS}

O controle de cães ferais, focando a restauração da integridade ecológica dos ecossistemas e das UCs, depende estritamente da intervenção humana por se tratar de uma espécie exótica invasora. Espécies exóticas instalam-se em UCs devido a diversos fatores como o desconhecimento do assunto até a hesitação em executar a remoção por parte tanto dos responsáveis pelo manejo no campo quanto por órgãos ambientais, que fazem o licenciamento dessa atividade.

Conforme Ruiz-Miranda et al. (2004), o primeiro passo para avaliar uma contaminação biológica é dividir a invasão em etapas: processos relacionados à chegada, à fase de estabelecimento, à fase de dispersão e à fase de integração.

- Chegada: são considerados fatores como o número de eventos, a quantidade e procedência dos indivíduos (pressão de propágulos) introduzidos, a natureza da espécie e o veículo de invasão (antrópico, natural). Essas informações são de grande importância nesta fase, pois a pressão de propágulos e o veículo terão enorme influência no sucesso da invasão.

- Estabelecimento: inclui questões sobre biologia de população e impactos observando se os animais introduzidos formam uma população autossustentável.

- Dispersão: fase que começa quando a população é autossustentável e a espécie começa a ampliar sua distribuição geográfica.

- Integração: espécie se torna residente e estabelece relações evolutivas e ecológicas com espécies nativas.

Há vários métodos de erradicação que recaem sob duas ações: remoção ou redução total da natalidade até levar à extinção local. Estes métodos podem ser combinados, passando a integrar programas abrangentes de controle de espécies invasoras. A remoção tem algumas dificuldades como: captura, transporte e alimentação, procedimentos de esterilização e éticas, associados aos diferentes destinos dos animais (eutanásia, centro de pesquisa, criadouro, repatriação). Além disto, 
deve haver um trabalho de conscientização dos moradores do entorno das UCs de modo a enriquecer o conhecimento sobre a flora e fauna local, bem como demonstrar atitudes que podem ser tomadas para minimizar o impacto nessas áreas protegidas (RUIZ-MIRANDA et al., 2004).

O licenciamento para remoção de espécies exóticas invasoras precisa ser livre de empecilhos legais (ZILLER, 2004) e por meio dessas e outras atitudes pode proceder a manejo correto e inverter o quadro de contaminação biológica em áreas protegidas e endêmicas. Segundo Ziller e Zalba (2007), geralmente são propostas três alternativas principais para correta destinação da fauna exótica invasora depois de capturada.

a. Depósitos em centros de triagem, criadouros e outras instituições assemelhadas:

Centros de triagem de fauna são os estabelecimentos mais comumente utilizados para a destinação de animais capturados. Tais opções, contudo, estão se tornando pouco viáveis porque a maioria desses locais não tem infraestrutura dimensionada para acomodar o grande número de animais capturados. Se não houver pessoas interessadas em se responsabilizar e cuidar desses animais, mesmo sendo de difícil manejo, há chances muito menores de se encontrar uma instituição que receba cães ou gatos domésticos, sobretudo se estiverem em estado feral.

\section{b. Eutanásia:}

Esta é outra opção de manejo de fauna introduzida a ser considerada como forma de controle de animais exóticos em UCs. Embora seja uma questão polêmica, em muitos casos, é a solução possível e adequada de destinação da fauna exótica, face às dificuldades em encontrar centros de triagem de fauna. Em muitos casos, é a única forma de eliminar também os riscos genéticos e ecológicos que a introdução indiscriminada e o repovoamento podem causar às populações de fauna silvestre nativa e aos ecossistemas. Critérios básicos, contudo, devem ser definidos como base para uma decisão. Primeiramente, a eutanásia deve ser feita apenas mediante o esgotamento ou impossibilidade de qualquer outra destinação que não leve o animal a óbito.

A seleção e aplicação do método devem estar de acordo com os mais altos princípios éticos e quando ocorram situações imprevistas, a técnica de eutanásia deverá ser selecionada por um médico veterinário. A pessoa que aplica o método de eutanásia deve ter experiência comprovada da técnica.

c. Destinação científica:

Neste caso, o uso de espécies exóticas teria uma grande importância, sobretudo se pensarmos na possibilidade de avaliação de conteúdo estomacal, que comprovasse ou não a predação de fauna silvestre no interior de UCs, e poderia contribuir com informações para o manejo das UCs, e com o uso de animais para práticas didático-científicas, especialmente se considerarmos convênios ou parcerias com as principais Instituições de Ensino Superior (IES).

No Brasil, foi publicado o Decreto Federal n. ${ }^{\circ} 24.645$ de 1934, que assegurava proteção a todos os animais, sem exceção. Somente em 1979, foi publicada a lei $\mathrm{n}^{\circ}$. 6.638 que estabeleceu normas para práticas didático-científica da vivissecção de animais, regulamentando o registro dos Biotérios e Centros de Experimentação, e estabelecendo penalidades para os infratores. Esta lei foi revogada pela Lei $\mathrm{n}^{\circ} 11.794$, de 8 de outubro de 2008, que regulamenta o inciso VII, do artigo $1^{\circ}$. do artigo 225 da Constituição Federal estabelecendo procedimentos para o uso científico de animais (BRASIL, 2008).

Além das medidas consideradas preventivas que podem ser tomadas nas UCs e entorno, deve-se precaver com relação aos equipamentos necessários para captura de indivíduos, caso não surtam efeitos as medidas preventivas e de orientação básicas. Segundo Ziller e Zalba (2007), no Paraná a orientação encaminhada aos técnicos de alguns escritórios regionais é a de solicitar que os moradores no entorno das UCs prendam seus cães e os alimentem de modo devido, sob a condição 
de que, caso sejam encontrados animais dentro de algum Parque ou outra categoria de UC, estes sejam erradicados.

Neste contexto, torna-se relevante pontuar que programas de erradicação de espécies exóticas, tanto animais, quanto vegetais, podem incluir uma ampla gama de metodologias, por exemplo, técnicas de caça terrestre e/ou aérea, armadilhas com atrativo alimentar ou sexual, envenenamento com iscas ou corte e retirada direta. Os programas, todavia, não devem negligenciar o previsto no artigo 32 da Lei . $^{\circ}$ 9.605/1998, que trata dos crimes relacionados aos maus-tratos a animais (BRASIL, 1998). Esse tem sido um dos principais pontos de resistência da sociedade às ações de erradicação de espécies de fauna exótica invasora.

Grupos de defesa dos direitos dos animais baseiam-se no artigo 32 da Lei n. ${ }^{\circ}$ 9.605/1998, sob a argumentação de que é crime ambiental maltratar animais, assim posicionando-se contra as ações de controle e erradicação de EEI's. Na maioria dos casos, no entanto, negligenciam os efeitos nocivos destas espécies exóticas às nativas, o que é considerado no artigo 37 da mesma lei. Mas, este não é um posicionamento exclusivo de grupos ativistas de direitos dos animais brasileiros. É compreensível o posicionamento destes grupos, especialmente se considerarmos os conflitos científicos, culturais, éticos e legais que envolvem a eliminação de organismos vivos.

Simultaneamente, evidencia-se a necessidade de incorporação da educação ambiental e adequada comunicação à sociedade sobre o que são espécies exóticas invasoras e quais são os seus riscos ao ambiente e à sociedade. A difusão das razões e das técnicas de manejo das espécies exóticas pode evitar que denúncias de controle destas sejam julgadas pela sociedade como crime ambiental, quando em verdade são ferramentas para a conservação da diversidade biológica. A adequada divulgação do tema e o envolvimento dos mais diversos segmentos da sociedade podem ajudar no estabelecimento de jurisprudência e regulamentação para o tema, tais como listas oficiais de espécies exóticas para referência pública, regulamentação para uso de espécies de valor comercial e análises de risco (ZILLER e ZALBA, 2007).

\section{CONCLUSÕES}

A invasão de espécies exóticas em UCs pode provocar impactos irreversíveis no ecossistema uma vez que se pode descobrir tarde demais a presença de determinada espécie invasora. Assim, existem sérios empecilhos como limitações de conhecimento do problema e tal fato, consequentemente, gera dificuldades de tomada de posição. Ainda, a inexistência de recursos financeiros imediatos e postura técnica e política institucional para encaminhar projetos e planos de manejo adequados, considerando-se neste caso tanto o tempo necessário para desenvolvê-los, como a agilidade na liberação dos recursos suficientes ou orçados, após aprovação.

Há a necessidade precípua de formação de técnicos que trabalham diretamente com as UCs, como gerentes e guardas-parque que, mediante orientação preliminar e apoio de profissionais especializados, poderão se posicionar perante aos problemas de várias origens que ocorrem atualmente, o que poderá evitar medidas equivocadas.

O investimento em formação e aparelhamento das UCs e das instituições que atendem os diversos problemas ambientais é o primeiro passo para sua resolução e a parceria com outras organizações é o caminho mais curto para resolvê-los, mesmo que a médio e longo prazos. É aconselhável, portanto, pôr em prática medidas eficazes visando diretamente no controle da população canina e a profilaxia de doenças potencialmente transmissíveis por estes animais. Para ser eficaz, este controle deve ser realizado dentro das UCs, bem como fora incluindo zonas rurais e urbanas. Estes animais devem permanecer junto aos seus donos sendo alimentados, vacinados e sem permissão de vagar livremente pelas ruas, e em UCs sendo proibida a sua entrada mesmo aconpanhados de seus proprietários. 
As informações compiladas reforçam a importância da implementação de medidas de comunicação social e educação ambiental, juntamente com os projetos que objetivam a erradicação de cães em UCs. Atenção especial deve ser dada ao processo de educação das comunidades locais quanto aos impactos causados por essa espécie, já que uma das finalidades, dentro dos planos de manejo deve ser a redução de riscos de introduções, sejam elas intencionais ou não. Os programas de erradicação terão maior chance de sucesso quando houver um apoio consciente dos atores sociais envolvidos no processo.

\section{REFERÊNCIAS}

ABDULLA, P.K.; JAMES, P.C.; SULOCHANA, S.; JAYAPRAKASAN, V.; PILLAI, RM. Anthrax in a Jaguar (Panthera onca). Journal of Zoo Animal Medicine, v.13, n.4, p.151-151, 1982.

BOITANI, L. Ecological and cultural diversities in the evolution of wolf-human relationships. In: CARBYN, L.N.; FRITTS, S.H.; SEIP, D.R. Ecology and conservation of wolves in a changing world. Edmontion, Alberta, Canadá: Canadian Circumpolar Institute, University of Alberta. 1995 , pp. 3-12.

BRASIL. Lei $\mathbf{N}^{0}$ 9.605, de 12 de fevereiro de 1998. Disponível em

<http://www.planalto.gov.br/ccivil_03/leis/19605.htm>. Acesso em janeiro de 2014.

BRASIL. Lei $\mathbf{N}^{\mathbf{0}}$. 11.794, de 8 de outubro de 2008. Disponível em

<http://www.planalto.gov.br/ccivil_03/_Ato2007-2010/2008/Lei/L11794.htm\#art27>. Acesso em janeiro de 2014.

BUTTLER, J.R.A.; DU TOIT, J.T.; BINGHAM, J. Free ranging domestic dogs (Canis familiaris) as predators and prey in rural Zimbabwe: threats of competition and disease to large wild carnivores. Biological Conservation, v. 15, n. 3, p.369-378, 2004.

CAMPOS, C.B. Impacto de cães (Canis familiaris) e gatos (Felis catus) errantes sobre a fauna silvestre em ambiente periurbano. 2004. 55p. Dissertação (Dissertação em Ecologia Aplicada, Área de Concentração Ecologia de Agroecossistemas). Centro de Energia Nuclear na Agricultura da Escola Superior d Agronomia "Luiz de Queiroz", USP, Piracicaba, SP, 2004.

CARVALHO, C.J.B. "Ferramentas atuais da biogeografia para utilização em conservação". In: IV Congresso Brasileiro de Unidades de Conservação. Curitiba: Fundação O Boticário de Proteção à Natureza/Rede Nacional Pró-Unidades de Conservação, v. 2, p 92-103, 2004.

CERQUEIRA, R.; FREITAS, S.R. A new study method of microhabitat structure of small mammals. Revista Brasileira de Biologia, v.59, n. 2, p.219-223, 1999.

CHIARELLO, A. Influência da caça ilegal sobre mamíferos e aves das matas de tabuleiros do norte do estado do Espírito Santo. Boletim do Museu de Biologia Mello Leitão, v. 11/12, p. 229-247, 2000. 
COSTA, E.O.; DINIZ, S.M.; FAVA-NETTO, C. Ecological aspects of fungal and bacterial infections of wild mammals in South America. Israel Journal of Veterinary Medicine, v. 52, n.4, p.137-140, 1997.

DIRZO, R.; MIRANDA, A. Altered patterns of herbivory and diversity in the forest understory: a case study of the possible consequences of contemporary defaunation. In: PRICE, P.W.; LEWINSOHN, T.M.; FERNANDES, G.W.; BENSON, W.W. (Eds.). Plant-animal interactions: evolutionary ecology. New York: Wiley and Sons Pub. 1991, pp 273-287.

FARACO, F.A.; LACERDA, A.C.R. “Contaminação biológica em unidades de conservação”. In: IV Congresso Brasileiro de Unidades de Conservação. Curitiba: Fundação O Boticário de Proteção à Natureza/Rede Nacional Pró-Unidades de Conservação, v. 2, p.78-84, 2004.

FARREL, L.E.; ROMAN, J.; SUNQUIST, M.E. Dietary separation of sympatric carnivores identified by molecular analysis of scats. Molecular Ecology, v. 9, n. 10, p.1583-1590, 2000.

GALETTI, M.; SAZIMA, I. Impacto de cães ferais em um fragmento urbano de Floresta Atlântica no sudeste do Brasil. Natureza e Conservação, v. 4, n. 1, p.58-63, 2006.

HALLWACHS, W. Agoutis (Dasyprocta punctata): the inheritors of guapinol (Hymenaea courbaril, Leguminosae). In: ESTRADA, A.; FLEMING, T. Frugivores seed dispersal. Dordrecht, Holanda: Dr. W. Junk Publishers. 1986, pp.285-304.

HOOGESTEIJN, R. Manual sobre os problemas de predação causados por onças-pintadas e onças-pardas em fazendas de gado. Rio de Janeiro: WCS, 2004. 28p.

LACERDA, A.C.R. TOMAS, W.M.; MARINHO-FILHO, J. Domestic dogs as an edge effect in the Brasília National Park, Brazil: interactions with native mammals. Animal Conservation, v. 12, p. 447-487, 2009.

LENNETTE, E.H.; EMMONS, R.W. "Health problems associated with the transportation and use of nondomestic animals: an overview". In: International symposium on health aspects of the international movement of animals. Washington, v.2, p.3-9, 1972.

MMA (MINISTÉRIO DO MEIO AMBIENTE). Convenção sobre Diversidade Biológica. Brasília - DF: MMA, 2000a. 30p.

MMA (MINISTÉRIO DO MEIO AMBIENTE). Avaliação e ações prioritárias para a conservação da biodiversidade da Mata Atlântica e Campos Sulinos. Brasília - DF: MMA, 2000b. 40p.

MIKICH, S.B.; OLIVEIRA, K.L. Revisão do Plano de Manejo do Parque Estadual Vila Rica do Espírito Santo, Fênix - PR. Curitiba: Mater Natura/ FNMA/ MMA. 2003. 452p.

OLIVEIRA, T.G.; CAVALCANTI, S.M.C. Identificação de Predadores de Animais Domésticos. In: LEITE-PITMAN, M.R.P.; OLIVEIRA, T.G.; PAULA, R.C.; INDUSTRIAK, C. Manual de Identificação, prevenção e controle de predadores carnívoros. Brasília: Ibama. 2002, pp. 31-50.

OLIVEIRA, V.B.; LINARES, A.M.; CORRÊA, G.L.C.; CHIARELLO, A.G. Predation on Black capuchin monkey Cebus nigritus (Primates: Cebiadae) by domestic dogs Canis lúpus familiaris 
(Carnivora: Canidae), in the Parque Estadual Serra do Brigadeiro, Minas Gerais, Brazil. Revista Brasileira de Zoologia, v. 25, n. 2, p. 376-378, 2008.

PALMEIRA, F.B.L.; BARRELLA, W. Conflitos causados pela predação de rebanhos domésticos por grandes felinos em comunidades quilombolas na Mata Atlântica. Biota Neotropica, v. 7, n. 1, p. 119-128, 2007.

PANG, J.; KLUETSCH, C.; ZOU, X.; ZHANG, A.; LUO, L.; ANGLEBY, H.; ARDALAN, A.; EKSTRÖM, C.; SKÖLLERMO, A.; LUNDEBERG, J.; MATSUMURA, S.; LEITNER, T.; ZHANG, Y.; SAVOLAINENT, P. mtDNA Data Indicate a Single Origin for Dogs South of Yangtze River, Less Than 16,300 Years Ago, from Numerous Wolves. Molecular Biology and Evolution, v. 26, n. 12, p. 2849-2864, 2009.

PITÉ, M.T.; AVELAR, T. Ecologia das populações e das comunidades: uma abordagem evolutiva do estudo da biodiversidade. Lisboa: Fundação Calouste Gulbenkian, 1996, 285p.

PRIMACK, R.B.; RODRIGUES, E. Biologia da conservação. Londrina, 2001, 327p.

RUIZ-MIRANDA, C.R.; MORAIS, M.M.; BECK, B.B.; VERONA, C.E. "O impacto de espécies invasoras em comunidades naturais - O Caso do mico-estrela vs. Mico-leão-dourado". In: IV Congresso Brasileiro de Unidades de Conservação. Curitiba: Fundação O Boticário de Proteção à Natureza/Rede Nacional Pró-Unidades de Conservação, v. 2, p. 64-73, 2004.

SRBEK-ARAUJO, A.C.; CHIARELLO, A.G. Domestic dogs in Atlantic forest preserves of southeastern Brazil: a camera-trapping study on patterns of entrance and site occupancy rates. Brazilian Journal of Biology, v. 68, n. 4, p.771-779, 2008.

THALMANN, O.; SHAPIRO, B.; CUI, P.; SCHUENEMANN, V.J.; SAWYER, S.K.; GREENFIELD, D.L.; GERMONPRÉ, M.B.; SABLIN, M.V.; LÓPEZ-GIRÁLDEZ, F.; DOMINGO-ROURA, X.; NAPIERALA, H.; UERPMANN, H-P.; LOPONTE, D.M.; ACOSTA, A.A.; GIEMSCH, L.; SCHMITZ, R.W.; WORTHINGTON, B.; BUIKSTRA, J.E.; DRUZHKOVA, A.; GRAPHODATSKY, A.S.; OVODOV, N.D.; WAHLBERG, N.; FREEDMAN, A.H.; SCHWEIZER, R. M.; KOEPFLI, K.-P.; LEONARD, J.A.; MEYER, M.; KRAUSE, J.; PÄÄBO, S.; GREEN, R.E.; WAYNE, R.K. Complete Mitochondrial Genomes of Ancient Canids Suggest a European Origin of Domestic Dogs. Science, v. 342, n. 6160, p.871-874, 2013.

TERBORGH, J. The role of felid predators in the neotropical forest. Vida Silvestre Neotropical, v. 2, n. 2, p.3-5, 1990.

VILELA, A.L.O. Aspectos da caça predatória de mamíferos no Parque Estadual Nova Baden Lambari, MG. 2009. 47 p. Monografia (trabalho de Conclusão do curso de ciências biológicas). Fundação Educacional de Machado, São Lourenço, Minas Gerais, 2009.

ZILLER, S.R. "Espécies invasoras em unidades de conservação". In: IV Congresso Brasileiro de Unidades de Conservação. Curitiba: Fundação O Boticário de Proteção à Natureza/Rede Nacional Pró-Unidades de Conservação, v. 2, p.74-77, 2004.

ZILLER, S.R.; ZALBA, S.M. Propostas de ação para prevenção e controle de espécies exóticas invasoras. Natureza \& Conservação, v. 5, n. 2, p.8-15, 2007. 